\title{
Constraint Programming Approach for Optimizing Business Asset Maintenance Strategy
}

\author{
Gilang Ramadhan ${ }^{\mathrm{a}^{*}}$ and Shu-Shun Liu ${ }^{\mathrm{b}}$ \\ ${ }^{a}$ Lecturer, Departement of Asset Management, Politeknik Negeri Bandung, Indonesia \\ ${ }^{\mathrm{b}}$ Associate Professor, Departement of Civil and Construction Engineering, National Yunlin University \\ of Science and Technology, Taiwan
}

Received o3 October 2018; accepted o7 January 2019

\begin{abstract}
There are many buildings with various conditions in Indonesia and some of them are not in finest conditions that need maintenance treatment urgently. The absence of building maintenance decision-making tool and limited budget are among main factors that cause unmanageable maintenance program. Therefore, this study has been conducted to propose an optimization model that is capable to determine the most appropriate building maintenance treatment. This study applied Constraint Programming (CP) approach to select the most economical maintenance treatment for a certain building and to allocate annual maintenance budget. CP-based model in this study subjects to constraint of budget and targeted level of building condition. In this study, maintenance treatment options, budget, time period, building deterioration rates, and the minimum standard of building condition were set. The model was run in IDM ILOG CPLEX Optimization Studio since the software is very efficient and effective in processing the optimization model. Furthermore, a case study was carried out to run the model involving 41 buildings in a 10- year period, and two different scenarios were conducted to examine the optimization model. TI1eresults successfully validated that the model can be a decision-making tool in selecting and prioritizing effective maintenance treatment.
\end{abstract}

\section{KEYWORDS}

Asset maintenance

Building maintenance

Constraint

programming

Optimization

\section{INTRODUCTION}

Building is one of important business assets of art institution or a company. Different institutions have various kinds of building with different functions. Some of the buildings are offices, schools, sports centers, convention halls, and many more. These types of building intend to facilitate users and owners' activities. To provide an excellent service, a building must be in good condition. However, condition level of buildings will decrease through its life cycle. Eventually, a proper maintenance program is needed to ensure sustainability of building condition (Lateef, 2010). Building maintenance is very important to make sure the sustainability of the buildings (Au Yong et al, 2014). Maintenance can protect the condition of a building in art acceptable state of service. 
Maintenance can be defined as a combination action executed to preserve parts of a building or renovate it to a standard condition (Flores-Colen et al., 2010). Moreover, building maintenance activities can lengthen the age of buildings in providing service for the owner and users.

Buildings need proper management to reach the most optimal efficiency (Grussing \& Liu, 2014). Buildings also demand an initial investment for the development and periodical expenses during their life cycle to rehabilitate them; otherwise, they will deteriorate and cannot provide proper services for users. During their service life, buildings also need continuous operational costs, including electricity, water, maintenance, and others. Buildings will deteriorate and become obsolescent rapidly if the management does not plan a proper investment; therefore, it will result in low performance. A further consequence of previous condition will lead a building to be less efficient in providing its primary services. Consequently, a building will need more operation cost and generate less income from its services.

Physical condition of a building will have reached a certain level that is lower than the previous condition because of its decreasing condition during its life cycle and the effects of maintenance works done in the previous periods (Wordsworth \& Lee, 2001). The recent functional capacity may become different from the previous function because of functional degradation and alteration to its new function based on the users' demands, such as renovations and development activities undertaken. Consequently, a slight alteration in the operation and maintenance of a building can have a major impact on the cost of ownership, the level of building condition and its functionality, and the performance of the building.

As a building deteriorates over time during its life cycle and because of the effect of maintenance works undertaken, its condition will keep changing. The recent physical condition is the result of degradation or maintenance works in the previous periods. Therefore, condition of a building is one of important aspects of building maintenance to be considered. Furthermore, by applying building condition index, building managers can formulate effective building maintenance strategies. Even the slightest alteration in building maintenance will affect the operating expenses and building sustainability. Therefore, a proper maintenance program will lead to an effective budget allocation and sustainable building performance (Flores-Colen \& de Brito, 2010).

However, it seems that building maintenance has not been an important issue in some parts of Indonesia (Arumsari \& Rarasati, 2017). Building maintenance is not taken into account by the owners. In consequence of low maintenance budget and an enormous number of buildings in various condition levels, a building maintenance program will only be planned when needed. As a result, high number of bad condition buildings is unavoidable and cannot give excellent services to users. In other circumstances, some buildings are maintained but at a high cost and inappropriate maintenance activities because of inefficient maintenance management and planning.

This problem must be solved to avert worse condition of buildings and higher maintenance budget. A proper strategy is needed to be implemented to overcome this problem. Because the condition of one building is different from the other buildings, the maintenance treatment will also be different for each building. Therefore, maintenance strategy optimization can determine the most appropriate maintenance activity for a particular building to achieve excellent condition and minimize maintenance cost.

Through implementing constraint programming method, this study intended to offer a decision-making tool to assist building managers in designing maintenance plan. This proposed 
model is a maintenance activity selection program employing constraint programming. This model could recommend the most efficient maintenance treatment for a certain building in a particular year to reach a standard of acceptable condition at the end of a maintenance plan period.

\section{LITERATURE REVIEW}

Maintenance optimization-related themes have been broadly examined by many researchers even though it is not exactly linked with building maintenance. Specifically, Markov prediction technique is extensively adopted to forecast upcoming pavement maintenance because of its capacity to incorporate restoration and pavement condition degradation rates in a certain transition probability matrix (Abaza et al., 2004). Markov model was applied by Abaza et al., (2004) to forecast forthcoming pavement performance and to establish a non-linear optimization approach in generating optimal pavement condition all over the network subject to budget constraints.

Another approach employed in network-level optimization topic is goal programming. This method is widely used because of its advantage in considering problems to encompass conflicting objectives with different levels of significance (Ravilara \& Givas, 1994). Prior research by Ravirala and Grivas (1994) has proved that goal programming is advantageous in gaining contradicting objectives concurrently.

Grussing and Liu (2014) constructed a method that is able to identify and to select multiyear building maintenance, repair, and renovation (MR\&R) works to maximize building performance and minimize life-cycle cost. Taillandier et al. (2017) proposed an innovative method to generate action plans for real estate properties maintenance optimization. The authors decomposed each building into components and stated the problem from Real Estate Property Maintenance Problem (REPAIRMP) into a multidimensional knapsack problem (MOMKP).

Lounis and Vanier (2000) constructed a multi-objective and stochastic system that combined probabilistic performance forecast and risk-assessment models with a multi-objective optimization method to optimize roofing maintenance management at a network level. Pun et al. (2017) designed a fuzzy-AHP-based decision support system (FADSS) to optimize maintenance work strategic planning. The approach aimed to support the multi-criteria decision-making process to establish the most cost-effective and efficient maintenance strategy.

Chiang et al. (2014) delivered a generic computational technique to generate the optimal solution for continuous building maintenance. Ostermeyer et al. (2013) presented a multidimensional Pareto optimization method using LCC and LCA to form SLCA in the constructed setting with a focus on renovations of housing buildings. Faghihinia and Mollaverdi (2012) built a multi-criterion decision-aided maintenance model incorporating three principles that have more effect on decision making; they are reliability, maintenance cost, and maintenance downtime. Molnarka and Koczy (2015) presented a new approach for generating an instrument that examined the costs and feasibilities of alternative maintenance process with real data gained from building diagnostics technical reports, surveys, and contractors' billing database.

Those previous studies show that various methods have been applied in the research of building maintenance, and different objects of building have been analyzed. However, constraint programming has not been involved in any building maintenance research focusing on the 
maintenance of a group of buildings by employing building condition index. Constraint programming is famous for its flexibility in problem declaration that makes scenario analysis conducted effectively. This present study proposed an alternative decision-making tool to optimize building maintenance strategy based on building condition index. The results of this study specified types of maintenance treatment for each building, time of maintenance activity implementation, and a total budget of all maintenance activities.

\section{CONSTRAINT PROGRAMMING}

In the recent decades, Constraint Programming (CP) is one of the widely discussed topics in programming language development area, especially in the artificial intelligence field (Barták, 1999). A constraint basically is a relation of some variables that have value declared in a domain. Constraint gives limitation toward possible value for a certain variable.

Nowadays, CP is mostly applied in optimization problems that need a real-time solution and that cannot be solved with mathematical programming. Generally, the problem includes logical programming that can be solved by constraint programming efficiently. Because of its capability in solving a complex problem, constraint programming is widely adopted to resolve combinatorial and optimization problems (Rossi et al., 2006). In addition, constraint programming is also applied in commercial fields, especially in planning and scheduling, sequencing, and configuration problems.

Heipcke (1999) affirms that CP for the combinatorial problem has three main advantages: (1) It has an efficient solution searching mechanism, (2) It has flexibility in types of constraints, and (3) It is convenient to formulate a model. According to Chan and $\mathrm{Hu}$ (2014), CP is an artificial intelligence which regards the problem resolving process as a searching procedure and efficiently employs the constraints in the process to find the optimum solution. Fruhwirth and Abdennadher (2003) states that CP is an application designed to resolve constraint satisfaction problems (CSPs) which are usually considered as combinatorial problems. Moreover, $\mathrm{CP}$ can be readily applied and has the flexibility in modelling different types of constraints, such as logical and sequential constraints (Liu \& Lu, 2018)

Liu and Wang (2011) addressed that consistency technique and systematic search strategies are crucial in resolving a problem in $\mathrm{CP}$. Consistency procedures construct a methodology in resolving CSPs, by omitting unreliable values from variables' domains until the solution for increasing search efficiency is acquired. There are several searching strategies to search solutions for combinatorial problems. They are generate-and-test (GT), back-tracking (BT), and forward checking (FC) (Liu \& Wang, 2012).

Furthermore, Liu and Wang (2012) explained those three searching strategies specifically. GT seeks and examines all potential solutions until one solution satisfying the constraints is gained. BT frequently assigns the consistency of variables in a recent incomplete solution prior to establishing the following process. If the incomplete solution breaks the constraints, the search is then backtracked to the most current consistent variable, so-and-so wiping out non-essential branching whilst searching for incomplete solutions. Therefore, this strategy is more effective than GT. In FC, unreliable values for the following variables are tentatively eliminated, and other existing values are replaced corresponding to the constraints associated with a recent variable. Accordingly, to increase search efficiency, FC employs much more constraint propagation than 
GT to examine the reliability of the variables. However, the total cost might be more expensive, and processing at every node could be more budget consuming. Therefore, bearing in mind the root of the problem and assessing the cost-benefit are very important in establishing an appropriate search strategy.

\section{MODEL FORMULATION}

\section{Conceptual Model}

This research aimed to develop a decision-making tool in selecting building maintenance treatment. CP was employed because it has high flexibility in problem statement that results effective scenario analysis. $\mathrm{CP}$ is not limited to the linear equations but allow the users to alter contents for accomplishing the required model (Heipcke, 1999).

The projected model aimed to obtain the most optimal solution for selecting an efficient maintenance strategy for every building employing binary variables, where 1 means that a treatment is implemented and o denotes otherwise. Under a set of constraints, the proposed model would select the most effective maintenance treatment for each building and determine the best time for maintenance treatment. Subsequently, two scenarios were conducted of which each represented different maintenance strategy. Scenario 1 was intended to achieve the minimum acceptable condition for every building in all years. In contrast, Scenario 2 demanded every building to achieve at least the minimum condition standard in the middle and at the end of a maintenance program period.

Managers generally have a lot of buildings with various condition levels. It is very essential to establish every category of building condition level. The data of buildings' condition level is very beneficial to choose the most appropriate maintenance action for particular building. The proposed model would examine the condition of buildings and the cost of each maintenance treatment to propose the best maintenance activity.

According to Elhakeem and Hegazy (2005), building condition is divided into five levels. They are Excellent, Good, Fair, Poor, and Critical. These criteria would be utilized to select appropriate maintenance treatment for a certain building. Furthermore, the five levels of building condition were converted into an index modified after Elhakeem and Hegazy (2005) work to make more simple calculation step in the optimization model. In the index, the highest point is 100, which represents excellent condition, and the lowest point is o, which represents critical condition. The goal is to improve building condition to reach acceptable condition level which is good condition. Forty-one (41) buildings data from Kusnadi's research (2011) were employed. Details of the initial condition and maintenance cost of these buildings are presented in Table 1.

Building degradation level or building deterioration rate is also very important in deciding the most effective maintenance treatment. Deterioration rate from the regulation of the Ministry of Public Work of Indonesia (2007) was employed in this study. The regulation states that the degradation of the building condition is $2 \%$ each year (Ministry of Public Work, 2007). The data of the initial condition in this research was determined deterministically and for the following years, $2 \%$ deterioration was used for each year in a 10-year maintenance plan period.

Furthermore, there are four types of maintenance treatment to upgrade buildings to a minimum standard condition level projected in this optimization model. The treatments are Repair, Rehabilitation, Renovation, and Restoration (Ministry of Public Work of Indonesia, 2007). 
Each treatment has a different impact in upgrading to a higher level of condition and improving building condition. The concept of the four maintenance treatments and its relation to the five building conditions are presented in Figure 1.

Table 1. Initial condition and maintenance cost of the buildings

\begin{tabular}{|c|c|c|c|c|c|c|}
\hline \multirow[b]{2}{*}{ No } & \multirow[b]{2}{*}{ Buildings } & \multirow{2}{*}{$\begin{array}{c}\text { Initial } \\
\text { Condition } \\
\text { Index } \\
\end{array}$} & \multicolumn{4}{|c|}{ Maintenance Cost (in IDR) } \\
\hline & & & Repair & Rehabilitation & Renovation & Restoration \\
\hline 1 & Tigaraksa I & 86.43 & $172,608,000$ & $241,651,200$ & $310,694,400$ & $448,780,800$ \\
\hline 2 & Tigaraksa II & 65.81 & $194,184,000$ & $271,857,600$ & $349,531,200$ & $504,878,400$ \\
\hline 3 & Tigaraksa III & 29.19 & $121,702,125$ & $170,382,975$ & $219,063,825$ & $316,425,525$ \\
\hline 4 & Tigaraksa IV & 82.10 & $86,304,000$ & $120,825,600$ & $155,347,200$ & $224,390,400$ \\
\hline 5 & Babakan & $83 \cdot 36$ & $121,702,125$ & $170,382,975$ & $219,063,825$ & $316,425,525$ \\
\hline 6 & Gudang & $74 \cdot 55$ & $121,702,125$ & $170,382,975$ & $219,063,825$ & $316,425,525$ \\
\hline 7 & Kadongdong & 44.06 & $148,672,125$ & $208,140,975$ & $267,609,825$ & $386,547,525$ \\
\hline 8 & Cogrek I & 92.34 & $140,244,000$ & $196,341,600$ & $252,439,200$ & $364,634,400$ \\
\hline 9 & Pasirnangka & 88.88 & $121,702,125$ & $170,382,975$ & $219,063,825$ & $316,425,525$ \\
\hline 10 & Seglog & 78.46 & $140,244,000$ & $196,341,600$ & $252,439,200$ & $364,634,400$ \\
\hline 11 & Pasirbolang & 66.71 & $140,244,000$ & $196,341,600$ & $252,439,200$ & $364,634,400$ \\
\hline 12 & Cogrek II & 80.11 & $140,244,000$ & $196,341,600$ & $252,439,200$ & $364,634,400$ \\
\hline 13 & Bidara & 73.15 & $121,702,125$ & $170,382,975$ & $219,063,825$ & $316,425,525$ \\
\hline 14 & Kadu & 40.01 & $172,608,000$ & $241,651,200$ & $310,694,400$ & $448,780,800$ \\
\hline 15 & Pete & 73.63 & $172,608,000$ & $241,651,200$ & $310,694,400$ & $448,780,800$ \\
\hline 16 & KalapaDua I & 91.77 & $129,45^{6,000}$ & $181,238,400$ & $233,020,800$ & $336,585,600$ \\
\hline 17 & KalapaDua II & 60.76 & $294,647,250$ & $412,506,150$ & $530,365,050$ & $766,082,850$ \\
\hline 18 & Cisereh I & $79 \cdot 73$ & $140,244,000$ & $196,341,600$ & $252,439,200$ & $364,634,400$ \\
\hline 19 & Cisereh II & 51.08 & $140,244,000$ & $196,341,600$ & $252,439,200$ & $364,634,400$ \\
\hline 20 & Guradog & 39.15 & $121,702,125$ & $170,382,975$ & $219,063,825$ & $316,425,525$ \\
\hline 21 & Sodong I & 92.40 & $172,608,000$ & $241,651,200$ & $310,694,400$ & $448,780,800$ \\
\hline 22 & Sodong II & 90.92 & $674,960,000$ & $944,944,000$ & $1,214,928,000$ & $1,754,896,000$ \\
\hline 23 & Tapos & 92.64 & $151,032,000$ & $211,444,800$ & $271,857,600$ & $392,683,200$ \\
\hline 24 & Pinang & $94 \cdot 35$ & $757,412,500$ & $1,060,377,500$ & $1,363,342,500$ & $1,969,272,500$ \\
\hline 25 & TaposWetan & $84 \cdot 35$ & $172,608,000$ & $241,651,200$ & $310,694,400$ & $448,780,800$ \\
\hline 26 & BanjarPanjan & $84 \cdot 39$ & $161,820,000$ & $226,548,000$ & $291,276,000$ & $420,732,000$ \\
\hline 27 & Peusar & 87.89 & $242,730,000$ & $339,822,000$ & $436,914,000$ & $631,098,000$ \\
\hline 28 & Cigaling & 86.64 & $172,608,000$ & $241,651,200$ & $310,694,400$ & $448,780,800$ \\
\hline 29 & Kedaper & 73.26 & $161,820,000$ & $226,548,000$ & $291,276,000$ & $420,732,000$ \\
\hline 30 & Cileles & 83.53 & $140,244,000$ & $196,341,600$ & $252,439,200$ & $364,634,400$ \\
\hline 31 & Jalupang & 79.63 & $172,608,000$ & $241,651,200$ & $310,694,400$ & $448,780,800$ \\
\hline 32 & Kaduagung I & 43.86 & $409,865,625$ & $573,811,875$ & $737,758,125$ & $1065,650,625$ \\
\hline 33 & Kaduagung II & 62.81 & $172,608,000$ & $241,651,200$ & $310,694,400$ & $448,780,800$ \\
\hline 34 & Bugel & 91.05 & $172,608,000$ & $241,651,200$ & $310,694,400$ & $448,780,800$ \\
\hline 35 & Matagara & 87.94 & $136,535,625$ & $191,149,875$ & $245,764,125$ & $354,992,625$ \\
\hline 36 & Nagrak & 76.04 & $402,190,125$ & $563,066,175$ & $723,942,225$ & $1045,694,325$ \\
\hline 37 & Tigaraksa V & 72.54 & $172,608,000$ & $241,651,200$ & $310,694,400$ & $448,780,800$ \\
\hline 38 & Tigaraksa VI & 90.82 & $148,672,125$ & $208,140,975$ & $267,609,825$ & $386,547,525$ \\
\hline 39 & Tigaraksa VII & 54.63 & $828,360,000$ & $1,159,704,000$ & $1,491,048,000$ & $2,153,736,000$ \\
\hline 40 & Tigaraksa VIII & 71.63 & $143,278,125$ & $200,589,375$ & $257,900,625$ & $372,523,125$ \\
\hline 41 & Tigaraksa IX & 83.78 & $839,865,000$ & $1,175,811,000$ & $1,511,757,000$ & $2,183,649,000$ \\
\hline
\end{tabular}




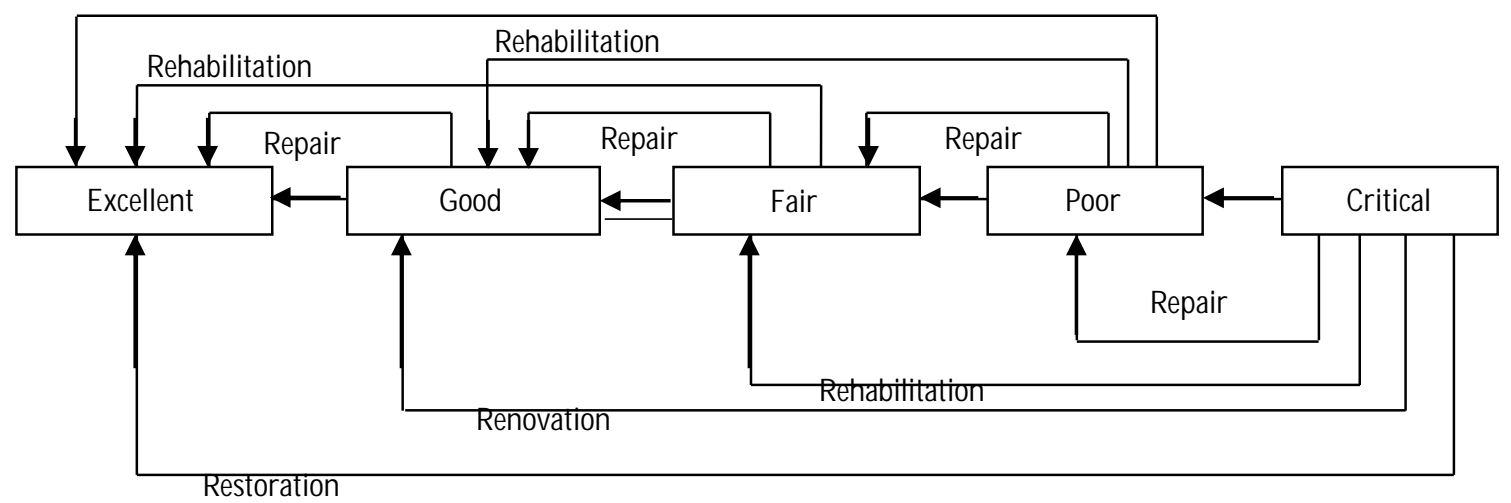

Figure 1. Building condition levels and building maintenance treatments modified after de la Garza et al. (2011)

\section{Model formulation}

CP model has been developed to find the least budget spent on maintenance treatments that satisfy all constraints. The variables, parameters, sets, constraints, and objective function are presented as follows.

$$
\begin{gathered}
\operatorname{Min} \sum_{i=1}^{i} \sum_{\substack{j=1 \\
\text { s.t. }}}^{j} \sum_{k=1}^{k} C_{i k} \cdot S_{i j k} \\
\sum_{\substack{i=1 \\
k}}^{i} \sum_{k=1}^{k} C_{i k} \cdot S_{i j k} \leq F_{j}, \forall j \in Y \\
\sum_{k=1}^{k} S_{i j k} \leq 1, \forall i \in B, \forall j \in Y \\
\sum_{k=1}^{k} S_{i j k} \cdot I_{k}+C B_{i j}=C A_{i j}, \forall i \in B, \forall j \in Y
\end{gathered}
$$

Renovation

$$
C B_{i j}=D_{i}, \forall i \in B, j=1
$$

$$
\begin{gathered}
C B_{i j+1}=C A_{i j} \cdot 0.98, \forall i \in B, \forall j \in Y \min \\
C A_{i j} \geq A, \forall i \in B, \forall j \in Y \\
C A_{i j} \geq A, \forall i \in B, j=5 \\
C A_{i j} \geq A, \forall i \in B, j=10 \\
C A_{i j} \leq M, \forall i \in B, \forall j \in Y
\end{gathered}
$$

The objective function in equation (1) enables the cost of each maintenance treatment to prioritize the most cost-effective treatment for each building in a particular year to minimize the total budget spent on all maintenance works. $\mathrm{C}$ is a parameter of the cost of treatment $k$ of building $i$. Next, $\mathrm{S}$ indicates binary variable for maintenance treatment selection, declaring maintenance treatment $k$ of building $i$ in year $j$, whether a particular treatment is selected $\left(S_{i j k}=1\right)$ or not $\left(S_{i j k}=0\right)$. 
Equation (2) is a constraint for the annual maintenance budget. $\mathrm{F}_{j}$ in the equation represents the amount of money in $j$ year. Maintenance cost spent on particular treatment of all buildings in a year must be less than or equal to maintenance budget in that year where B is a set of buildings and $\mathrm{Y}$ is set for years. Equation (3) limits to select only one treatment for a particular building in a year or not to perform any maintenance action at all. Equation (4) aims to deliver information about the condition after $S_{i j k}$ maintenance treatment is implemented to building $i$ in a year (year $j$ ). $\mathrm{I}_{k}$ in the constraint denotes a treatment $k$ improvement. Furthermore, $\mathrm{CB}_{i j}$ defines the building $i$ condition in year $j$ prior to a maintenance treatment is undertaken and $\mathrm{CA}_{i j}$ describes the building $i$ condition in year $j$ after a maintenance treatment is employed.

Equation (5) indicates building condition at the beginning of the first year (baseline) where $\mathrm{D}_{i}$ represents the damage of building $i$. Equation (6) calculates the deterioration of buildings condition in each year. $2 \%$ deterioration rate per year is established, consequently, $\mathrm{CA}_{i j}$ is multiplied by 0.98 to obtain the building condition index value at the beginning of the following year $\left(\mathrm{CB}_{i j+1}\right)$. Equation (7) demands all buildings have to be bigger than or equal to a minimum standard level of building condition in each year. In this study, 75 was the minimum acceptable standard of building condition (A) and this constraint was employed in Scenario 1 but then was removed from Scenario 2 because of different objective. Otherwise, equation (8) and equation (9) demand all buildings to achieve the minimum acceptable condition at least in the middle and at the end of the period. In addition, these two constraints were generated in Scenario 2 but were not involved in Scenario 1. Finally, equation (10) limits the condition of all buildings that must be less than or equal to a maximum building condition (M) which is 100.

IBM ILOG CPLEX Optimization Studio software was utilized to execute the model and to obtain the optimal solution. This software is very effective and efficient in solving an optimization problem. In addition, the software is convenient to run a constraint programming optimization model because the model can be declared in a simple language and notation. This software allows users to divide the optimization model from the data; as a result, the same model can be run easily with different data.

\section{CASE STUDY AND RESULTS}

The model of this research has been implemented to optimize maintenance strategy in a school building network in Tangerang, Indonesia. There are forty-one (41) buildings in this network in different initial conditions. There are four options of maintenance treatment with different cost for each building that can be implemented on every building. The projected model would try to choose the most cost-effective maintenance treatment for each building and to reach the minimum acceptable condition corresponding to the objective of each scenario.

\section{Results of Scenario 1}

The objective of Scenario 1 is to maintain buildings to reach the minimum level of condition in every year within a 10-year period. In this scenario, deteriorated buildings which are below the minimum standard condition will be directly maintained to achieve the objective. The proposed model in this scenario selected the most appropriate maintenance action to improve the condition of buildings corresponding to their initial conditions. It was also expected that total maintenance 
budget during the given period could be calculated to facilitate building managers to do budgeting for all building maintenance activities.

The model in Scenario 1 employed objective function which is represented by equation (1) as described in Section 4. Furthermore, almost all constraints were used except equation (8) and equation (9). The results of Scenario 1 are shown in Table 2. The table presents the maintenance treatment that has been selected for every building and the year of maintenance execution. Scenario 1 requires all buildings to be above the minimum acceptable condition in every year during the given period.

The table shows that maintenance of most of the buildings is categorized into repair maintenance treatment executed in different years. Repair treatment is able to upgrade building condition to one level above the current condition. For example, Gudang, Bidara, Pete, Kedaper, Tigaraksa V, and Tigaraksa VIII are buildings in fair condition at the beginning of the period; therefore, repair treatment in the first year is recommended to upgrade their condition to be above the minimum standard. However, good condition buildings will be repaired after the first year because their condition is above the minimum level of condition at the beginning of the period, for instance, Tigaraksa I in the ninth year, Babakan in the seventh year, Seglog in the fourth year, etc.

There are four buildings which are recommended for rehabilitation treatment in the first year. The buildings are Tigaraksa II, Pasirbolang, Kalapa Dua II, and Kaduagung II. These four buildings are in poor condition in the first year; as a result, they have to be rehabilitated to achieve the minimum acceptable condition. Rehabilitation treatment can improve building condition to two levels above the current condition.

Five buildings, which are Kadongdong, Kadu, Cisereh II, Kaduagung I and Tigaraksa VII, need to be renovated. These buildings are in poor condition but still in the upper range; hence, renovation is suitable to improve their condition and can upgrade the condition to three levels above the current condition. Tigaraksa III and Guradog buildings are in the lower range of poor condition. Consequently, renovation is the only treatment that can upgrade the building to be above the minimum acceptable degree. Restoration treatment is able to improve building condition four levels above the initial condition.

Some buildings require maintenance treatment twice throughout the period. For instance, Kaduagung I and Tigaraksa III buildings require to have repair treatment in the seventh year and in the tenth year because their condition are below the minimum standard. In total, there are 4 buildings which should be repaired twice. However, there is no maintenance action undertaken in the eighth year because in this year there is no building which is below minimum acceptable condition.

Meanwhile, eight buildings, which are Cogrek I, Sodong I, Kalapa Dua I, Sodong II, Tapos, Pinang, Bugel, and Tigaraksa VI, will not get any maintenance treatment during the 10-year period because they have been in excellent condition since the first year. In other words, until the end of the period, their conditions are still above the minimum acceptable level. 
Table 2. Results of scenario 1

\begin{tabular}{|c|c|c|}
\hline Building & $\begin{array}{c}\text { Maintenance } \\
\text { Strategy }\end{array}$ & $\begin{array}{c}\text { Year of } \\
\text { Maintenance }\end{array}$ \\
\hline Tigaraksa I & Repair & $9^{\text {th }}$ \\
\hline Tigaraksa II & Rehabilitation & $1^{\mathrm{st}}$ \\
\hline \multirow{2}{*}{ Tigaraksa III } & Restoration & $1^{\mathrm{st}}$ \\
\hline & Repair & $10^{\text {th }}$ \\
\hline Tigaraksa IV & Repair & $6^{\text {th }}$ \\
\hline Babakan & Repair & $7^{\text {th }}$ \\
\hline Gudang & Repair & $1^{\text {st }}$ \\
\hline \multirow{2}{*}{ Kadongdong } & Renovation & $1^{\text {st }}$ \\
\hline & Repair & $7^{\text {th }}$ \\
\hline Cogrek I & No Maintenance & - \\
\hline Pasirnangka & Repair & $10^{\text {th }}$ \\
\hline Seglog & Repair & $4^{\text {th }}$ \\
\hline Pasirbolang & Rehabilitation & $1^{\text {st }}$ \\
\hline Cogrek II & Repair & $5^{\text {th }}$ \\
\hline Bidara & Repair & $1^{\text {st }}$ \\
\hline \multirow{2}{*}{ Kadu } & Renovation & $1^{\text {st }}$ \\
\hline & Repair & $5^{\text {th }}$ \\
\hline Pete & Repair & $1^{\text {st }}$ \\
\hline KalapaDua I & No Maintenance & - \\
\hline KalapaDua II & Rehabilitation & $1^{\text {st }}$ \\
\hline Cisereh I & Repair & $5^{\text {th }}$ \\
\hline Cisereh II & Renovation & $1^{\text {st }}$ \\
\hline Guradog & Restoration & $1^{\text {st }}$ \\
\hline Sodong I & No Maintenance & - \\
\hline Sodong II & No Maintenance & - \\
\hline Tapos & No Maintenance & - \\
\hline Pinang & No Maintenance & - \\
\hline TaposWetan & Repair & $7^{\text {th }}$ \\
\hline Banjar Panjang & Repair & $7^{\text {th }}$ \\
\hline Peusar & Repair & $9^{\text {th }}$ \\
\hline Cigaling & Repair & $9^{\text {th }}$ \\
\hline Kedaper & Repair & $1^{\mathrm{st}}$ \\
\hline Cileles & Repair & $7^{\text {th }}$ \\
\hline Jalupang & Repair & $4^{\text {th }}$ \\
\hline \multirow{2}{*}{ Kaduagung I } & Renovation & $1^{\text {st }}$ \\
\hline & Repair & $7^{\text {th }}$ \\
\hline Kaduagung II & Rehabilitation & $1^{\text {st }}$ \\
\hline Bugel & No Maintenance & - \\
\hline Matagara & Repair & $9^{\text {th }}$ \\
\hline Nagrak & Repair & $2^{\text {nd }}$ \\
\hline Tigaraksa V & Repair & $1^{\text {st }}$ \\
\hline Tigaraksa VI & No Maintenance & - \\
\hline Tigaraksa VII & Renovation & $1^{\mathrm{st}}$ \\
\hline Tigaraksa VIII & Repair & $1^{\text {st }}$ \\
\hline Tigaraksa IX & Repair & $7^{\text {th }}$ \\
\hline
\end{tabular}

In term of building condition level, the results of Scenario 1 are presented in Figure 2. It shows 10 samples of buildings representing various preliminary conditions. The fair and the poor initial condition buildings are buildings that have been maintained to achieve minimum level of condition and some of these building have been maintained twice. On the other hand, good condition buildings will be maintained after the condition deteriorates to below 75 . However, 
maintenance treatments will not be carried out to the buildings in excellent condition until the end of the period. Therefore, all buildings will be above the minimum acceptable standard until the end of the period.

Total budget spent every year on maintenance treatments of Scenario 1 is presented in Figure 3. Because many buildings need to be repaired in the beginning of the period, Scenario 1 spends a lot of money in the first year to execute maintenance activities for some buildings. In contrast, the maintenance expenses in the following years will be much smaller because there are only a small number of buildings that deteriorate to below the minimum standard every year. In 10 years, approximately IDR 9.9 billion would be spent to implement all maintenance activities in this scenario.

The results of Scenario 1 successfully validate the proposed model to incorporate budget limit and condition requirement to minimize the total maintenance cost of selected maintenance treatments. Therefore, managers are able to monitor the conditions of the buildings and determine the time for building maintenance. Maintenance budget during the given period is also presented so that managers can do effective budgeting from the beginning.

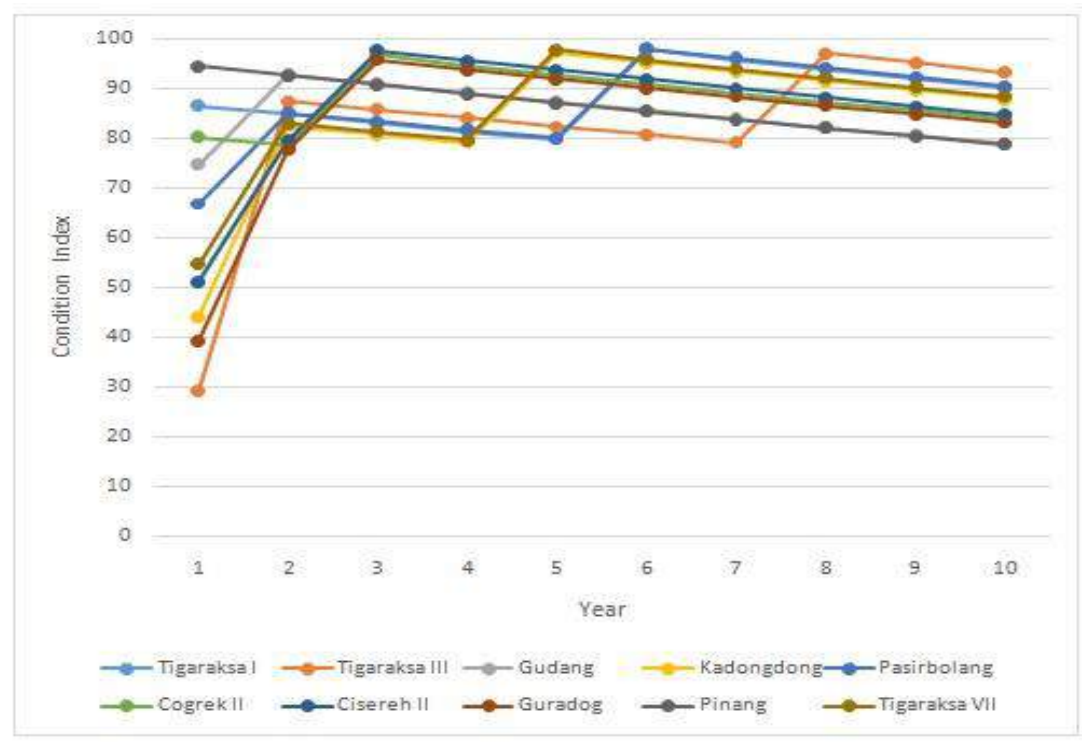

Figure 2. Scenario 1 buildings' condition performance 


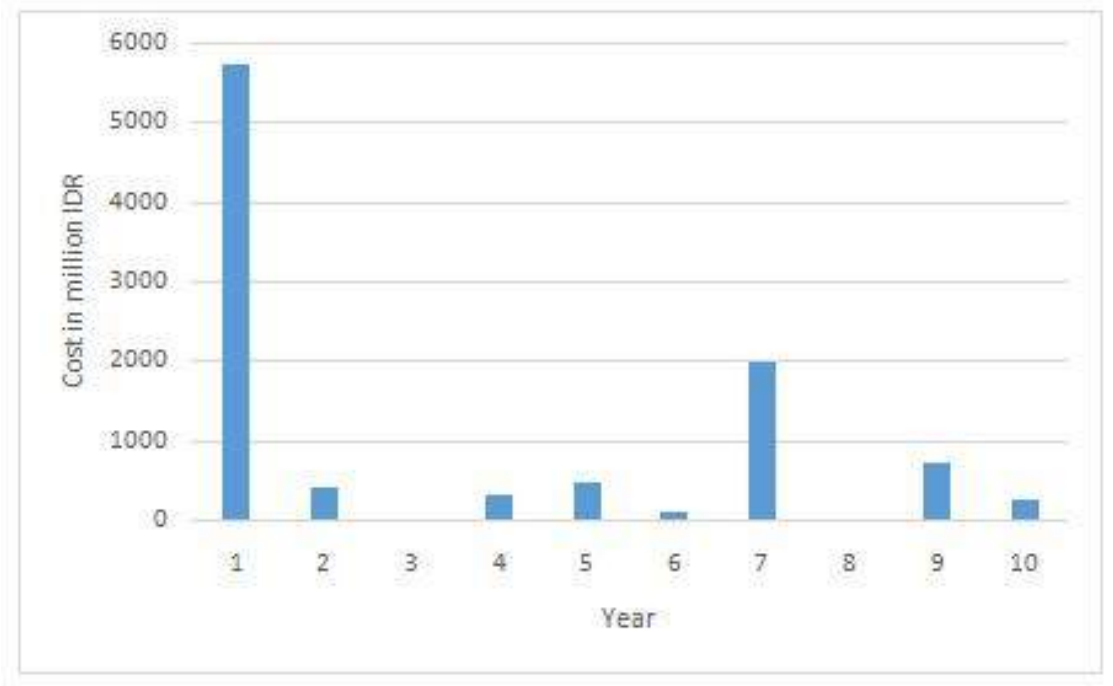

Figure 3. Scenario 1 yearly maintenance spending

\section{Results of Scenario 2}

Unlike Scenario 1, the objective of Scenario 2 is to maintain the buildings to reach the minimum acceptable condition in the middle and at the end of the period. The objective allows some buildings to deteriorate to below the minimum standard in certain years and may delay some maintenance activities for the deteriorated buildings. The most suitable maintenance treatment will be selected for each building and the total budget for all maintenance activities during the given period will be obtained in this scenario.

The model applied in Scenario 2 is almost the same as Scenario 1, but the equations have been changed by omitting equation (7) and employing equation (8) and equation (9). The purpose of Scenario 2 is to demand all buildings to have greater condition index than the minimum standard condition in the middle and at the end of the given period. Nevertheless, this scenario does not take into account the building condition each year. The results of the Scenario 2 are shown in Table 3.

Like in Scenario 1, Repair treatment is the most selected maintenance treatment in Scenario 2. Almost all buildings are under category of repair treatment at a different time in the given period, $t$ mostly in the fifth year. For example, Gudang building would not be repaired in the first year like in Scenario 1, but it would be repaired in the fifth year.

Compared to Scenario 1, in Scenario 2, more buildings should be rehabilitated. There are eight buildings that will get rehabilitation; they are Tigaraksa II, Kadongdong, Pasirbolang, Kadu, Kalapa Dua II, Guradog, Kaduagung I and Kaduagung II. These rehabilitation treatments will be conducted from the third year to the fifth year, but more than half of the treatments will be carried out in the fifth year. This condition occurs because one of the constraints in Scenario 2 requires every building to achieve the minimum standard in the middle of the period.

The number of buildings that are renovated in Scenario 2 is less than in Scenario 1. They are Cisereh II and Tigaraksa VII. In Scenario 2, Cisereh II and Tigaraksa VII buildings, which are determined to be renovated in the first year of Scenario 1, are renovated in the second year and fourth year respectively. 
In contrast to Scenario 1, in Scenario 2 only one building is maintained by Restoration treatment. In Scenario 2, Tigaraksa III is maintained with Restoration, while Guradog which is maintained with Restoration in Scenario 1 is maintained with Rehabilitation in the fifth year after getting Repair treatment in the second year. As in Scenario 1, four buildings get the second maintenance treatment in Scenario 2. However, one of these four buildings is different. In Scenario 1, Tigaraksa III is one of the buildings that requires second maintenance, but the position is replaced by Guradog in Scenario 2.

There are no maintenance activities in the eighth year. Almost all buildings have already been repaired in the middle of the period to satisfy the two special constraints in Scenario 2. The two constraints demand all buildings have to meet the minimum standard condition in the middle and at the end of the period.

Scenario 2 does not take into account the performance of building condition each year. Figure 4 shows that the model allows some buildings worsen to below the minimum standard and then repairs them in the middle and at the end of the period to reach the minimum acceptable condition in the tenth year. For example, Pasirbolang, Kalapa Dua II, and Kaduagung II buildings are not maintained right away in the commencement years even though their initial conditions are lower than the minimum condition level. Meanwhile, Tigaraksa III building, which is in the lower range of poor condition, is repaired in the first year, but it has not achieved the minimum acceptable condition yet. Its condition will be decreasing until the ninth year and then gets the second maintenance to reach the minimum standard in the tenth year.

Figure 5 shows the money spent on all maintenance activities throughout the 10-year period. Unlike Scenario 1, much more money is spent in Scenario 2 in the middle of the given period because some buildings need to be maintained to reach the minimum acceptable condition in the middle of the period. After the fifth year, the spending is much smaller, but then it is increasing slightly in the tenth year. This condition happens because the majority of the buildings is repaired in the middle of the period and will get the second maintenance in the last years of the period. Ultimately, approximately IDR 9.5 billion is needed to fund all the buildings maintenance activities. This scenario is more cost-effective than Scenario 1. 
Table 3. Results of scenario 2

\begin{tabular}{|c|c|c|}
\hline Building & $\begin{array}{c}\text { Maintenance } \\
\text { Strategy }\end{array}$ & $\begin{array}{c}\text { Year of } \\
\text { Maintenance }\end{array}$ \\
\hline Tigaraksa I & Repair & $9^{\text {th }}$ \\
\hline Tigaraksa II & Rehabilitation & $3^{\text {rd }}$ \\
\hline Tigaraksa III & Restoration & $4^{\text {th }}$ \\
\hline Tigaraksa IV & Repair & $10^{\text {th }}$ \\
\hline Babakan & Repair & $10^{\text {th }}$ \\
\hline Gudang & Repair & $5^{\text {th }}$ \\
\hline \multirow{2}{*}{ Kadongdong } & Repair & $4^{\text {th }}$ \\
\hline & Rehabilitation & $5^{\text {th }}$ \\
\hline Cogrek I & No Maintenance & - \\
\hline Pasirnangka & Repair & $7^{\text {th }}$ \\
\hline Seglog & Repair & $5^{\text {th }}$ \\
\hline Pasirbolang & Rehabilitation & $5^{\text {th }}$ \\
\hline Cogrek II & Repair & $2^{\text {nd }}$ \\
\hline Bidara & Repair & $5^{\text {th }}$ \\
\hline \multirow{2}{*}{ Kadu } & Repair & $2^{\text {nd }}$ \\
\hline & Rehabilitation & $5^{\text {th }}$ \\
\hline Pete & Repair & $5^{\text {th }}$ \\
\hline Kalapa Dua I & No Maintenance & - \\
\hline Kalapa Dua II & Rehabilitation & $4^{\text {th }}$ \\
\hline Cisereh I & Repair & $5^{\text {th }}$ \\
\hline Cisereh II & Renovation & $4^{\text {th }}$ \\
\hline \multirow{2}{*}{ Guradog } & Repair & $2^{\text {nd }}$ \\
\hline & Rehabilitation & $5^{\text {th }}$ \\
\hline Sodong I & No Maintenance & - \\
\hline Sodong II & No Maintenance & - \\
\hline Tapos & No Maintenance & - \\
\hline Pinang & No Maintenance & - \\
\hline Tapos Wetan & Repair & $4^{\text {th }}$ \\
\hline Banjar Panjang & Repair & $4^{\text {th }}$ \\
\hline Peusar & Repair & $6^{\text {th }}$ \\
\hline Cigaling & Repair & $9^{\text {th }}$ \\
\hline Kedaper & Repair & $5^{\text {th }}$ \\
\hline Cileles & Repair & $10^{\text {th }}$ \\
\hline Jalupang & Repair & $1^{\text {st }}$ \\
\hline \multirow{2}{*}{ Kaduagung I } & Repair & $4^{\text {th }}$ \\
\hline & Rehabilitation & $5^{\text {th }}$ \\
\hline Kaduagung II & Rehabilitation & $3^{\text {rd }}$ \\
\hline Bugel & No Maintenance & - \\
\hline Matagara & Repair & $6^{\text {th }}$ \\
\hline Nagrak & Repair & $5^{\text {th }}$ \\
\hline Tigaraksa V & Repair & $5^{\text {th }}$ \\
\hline Tigaraksa VI & No Maintenance & - \\
\hline Tigaraksa VII & Renovation & $2^{\text {nd }}$ \\
\hline Tigaraksa VIII & Repair & $5^{\text {th }}$ \\
\hline Tigaraksa IX & Repair & $10^{\text {th }}$ \\
\hline
\end{tabular}




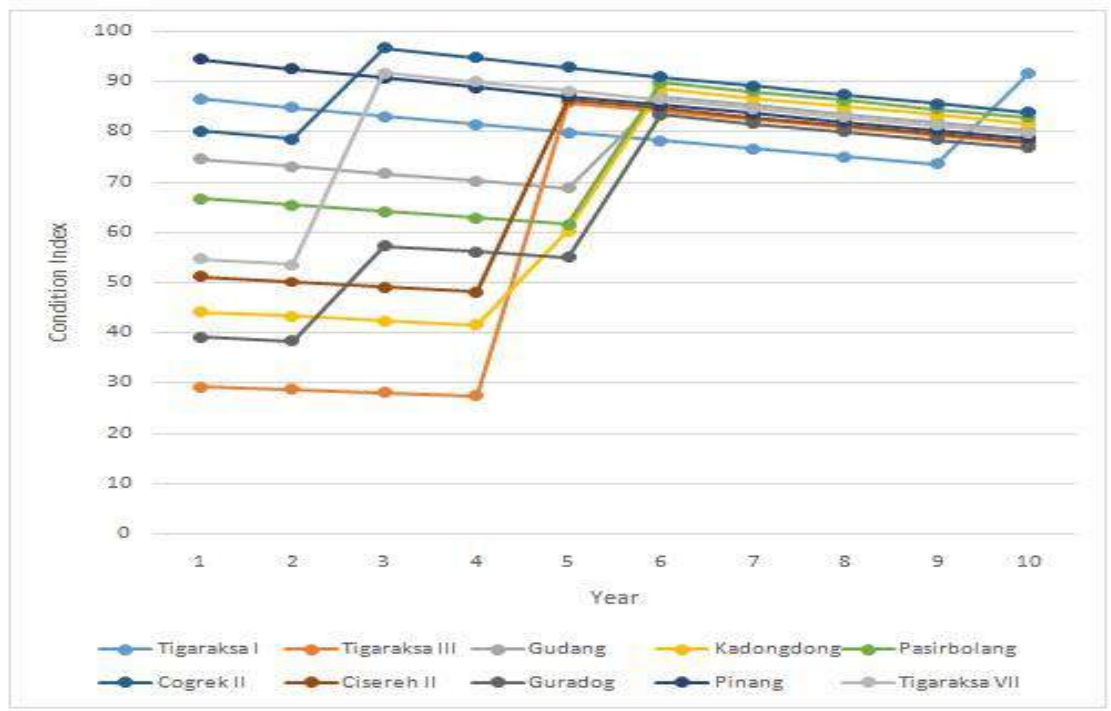

Figure 4. Scenario 2 buildings condition performance

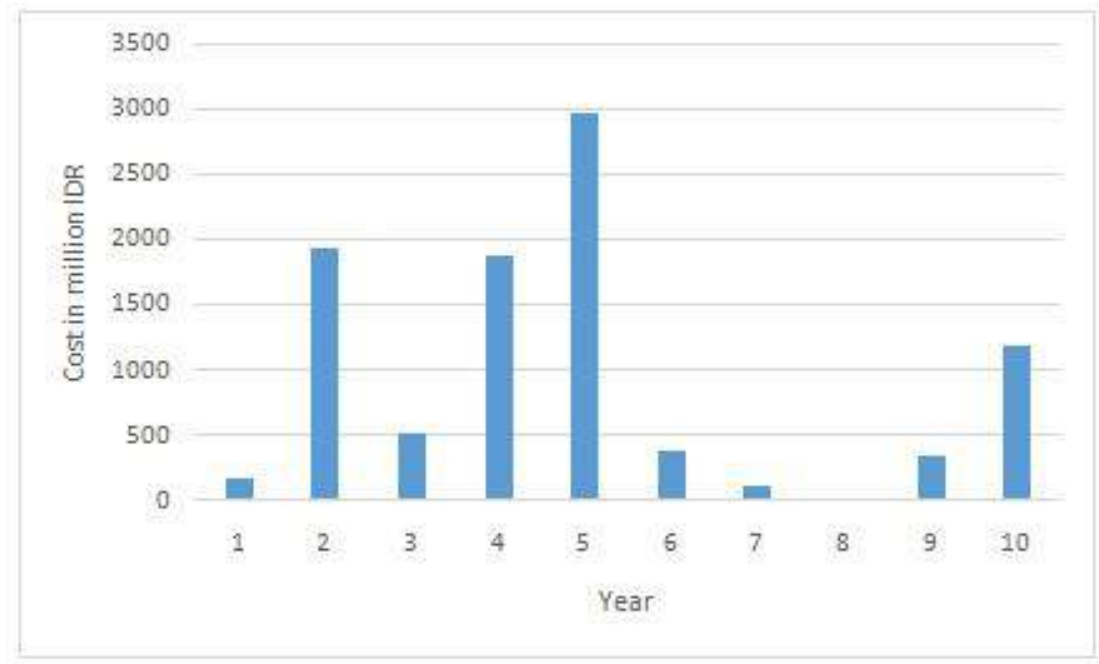

Figure 5. Scenario 2 yearly maintenance spending

The model in Scenario 2 succeeded in satisfying additional constraints, which require all buildings to be above the minimum acceptable conditions in the middle and at the end of the given period. The model will let some buildings deteriorate to below the standard but not for a very long time. The buildings are maintained mostly in the fourth and fifth year. As in Scenario 1, the results of Scenario 2 allow managers to plan all maintenance activities including the overall budget effectively from the beginning of the period.

\section{CONCLUSION AND FUTURE RESEARCH}

This study examined the condition level of buildings and spending on maintenance treatments each year. Applying constraint programming approach, a maintenance optimization model is 
projected to resolve maintenance treatment selection problems. This constraint programming framework enables to develop strategic level planning by allowing building managers to examine an alternative solution for building maintenance problems. The proposed model has been proved to be a decision-making tool in assisting building managers to solve building maintenance problems in a network-level. The results indicated that integrating a proper decision-making instrument is useful in planning an effective building maintenance program.

The proposed model has been validated by generating two scenarios of which each has different objectives. Scenario 1 requires every building to have the greater condition than the minimum standard level in each year during the period. On the other hand, Scenario 2 only demands all buildings to achieve the standard condition in the middle and at the end of the period. The two scenarios involved forty-one (41) buildings with various initial conditions in 10-year maintenance plan period.

These findings can assist managers to forecast the schedule of building repairs and the most efficient and effective maintenance treatment. Moreover, managers can organize maintenance treatments for every building and prepare the resources for maintenance treatments. In addition, the model can help managers to monitor the condition of buildings throughout the building condition index.

Managers can also estimate the budget required for maintenance activities every year, and they can plan the most effective maintenance budgeting for a particular time period. Managers can take into consideration which approach is more appropriate, whether maintaining the buildings' condition above the minimum acceptable condition but needs higher cost or aiming the buildings to reach the minimum acceptable standard in the middle and at the end of the period with lower budget but allow some buildings to deteriorate to below the minimum standard. The model proposed is proven as a budgeting tool for building maintenance planning. For total budget concern in a 10-year maintenance period, Scenario 2 needs lower maintenance budget than Scenario 1.

This research has some restrictions and uses some assumptions that lead to the limitation of the research. This study only addresses a network-level optimization model and does not consider the project-level optimization model. Furthermore, the study only considers building condition index and maintenance treatment cost as the main factors. Ultimately, the available yearly budget is the only resource that is taken into account in this research.

Those restrictions will lead to some challenges for future research in building maintenance study area. There is a larger scope that can be explored to conduct more advanced research in the future. By adding more criteria and considering other factors that are related to building maintenance field, it can generate better research results. One possible improvement for future research is by incorporating project-level optimization. Activities relationship among buildings in a network-level can be included to optimize building maintenance program. In addition, other resources, such as human resource and equipment can be taken into account as decision-making consideration. As a result, it can be regarded as resource-constrained project scheduling problems (RCPSP). This approach can provide a different point of view that can complement the results of the previous study. 


\section{REFERENCES}

Abaza, A. K., Ashur, S. A., \& Al-Khatib, I. (2004). An Integrated Pavement Management System With a Markovian Prediction Model. Journal of Transportation Engineering, 13o(1): 24-33. doi: 10.1061/(ASCE)0733-947X(2004)130:1(24)

Arumsari, P., \& Rarasati, A. D. (2017). Maintenance Strategy for Public-Rented Residential Building: A Case Study in Jakarta, Indonesia. Built Environment Project and Asset Management, 7(1), 99110.

Au-Yong, C., Ali, A. S., \& Ahmad, F. (2014). Significant Characteristics of Scheduled and ConditionBased Maintenance in Office Buildings. Journal of Performance of Construction Facilities, 28(2): 257-263. doi: 10.1061/(ASCE)CF.1943-5509.0000432

Badr, A. M., \& Brown, K. N. (2010). Building Maintenance Scheduling Using Cost-Based Reasoning and Constraint Programming Techniques. eWork and eBusiness in Architecture, Engineering, and Construction-Menzel Scherer (Eds). London.

Barták, R. (1999). Constraint programming: In pursuit of the holy grail. In Proceedings of the Week of Doctoral Students (WDS99) (pp. 555-564). Prague: MatFyzPress.

Brailsford, S. C., Potts, C. N., \& Smith, B. M. (1999). Constraint Satisfaction Problem: Algorithms and Application. European Journal of Operational Research, 119(3): 557-581.

Chan, W., \& Hu, H. (2002). Constraint Programming Approach to Precast Production Scheduling. Journal of Construction Engineering and Management, 128(6): 513-521. doi: 10.1061/(ASCE)0733-9364(2002)128:6(513)

de la Garza, J. M., Akylidiz, S., Bish, D. R., \& Krueger, D. A. (2011). Network-Level Optimization of Pavement Maintenance Renewal Strategies. Advanced Engineering Informatics, 25(4): 699-712. doi:10.1016/j.aei.2011.08.002

Elhakeem, A., \& Hegazy, T. (2005). Toward a Visual Guidance System for Condition Assessment of the Building Infrastructure. Proceedings of 1st CSCE Speciality Conference on Infrastructure Technologies, Management, and Policy, (pp. 1718-1725). Toronto.

Faghihinia, E., \& Mollaverdi, N. (2012). Building a Maintenance Policy through a Multi-Criterion Decision-Making Model. Journal of Industrial Engineering International, 8:14. doi: 10.1186/2251712X-8-14

Flores-Colen, I., \& de Brito, J. (2010). A Systematic Approach for Maintenance Budgeting of Buildings Façades Based on Predictive and Preventive Strategies. Construction and Building Materials, 24(9), 1718-1729. doi:10.1016/j.conbuildmat.2010.02.017

Flores-Colen, I., de Brito, J., \& Freitas, V. (2010). Discussion of Criteria for Prioritization of Predictive Maintenance of Building Facades: Survey of 30 Experts. Journal of Performance Construction Facilities, 337-344. doi: 10.1061/ASCECF.1943-5509.0000104

Fruhwirth, T. W., \& Abdennadher, S. (2003). Essentials of Constraint Programming 1st ed. Berlin: Springer.

Grussing, M. N., \& Liu, L. Y. (2014). Knowledge-Based Optimization of Building Maintenance, Repair, and Renovation Activities to Improve Facility Life Cycle Investments. Journal of Performance of Constructed Facilities, 28(3): 539-548. doi: 10.1061/(ASCE)CF.1943-5509.0000449

Heipcke, S. (1999). Combined Modelling and Problem-Solving in Mathematical Programming and Constraint Programming. Buckingham: University of Buckingham.

Kusnadi, E. (2011). Sistem Pendukung Keputusan Pemeliharaan Bangunan Sekolah Negeri. Surakarta: Universitas Sebelas Maret.

Lateef, O. A. (2010). Quantitative Analysis of Criteria in University Building Maintenance in Malaysia. Australasian Journal of Construction Economics and Building, 51-61.

Liu, J., \& Lu, M. (2018). Constraint Programming Approach to Optimizing Project Schedule under Material Logistics and Crew Availability Constraints. Journal Construction Engineering and Management, 144(7): 04018049. doi: 10.1061/(ASCE)CO.1943-7862.0001507 
Liu, S. S., \& Wang, C. J. (2011). Optimizing Project Selection and Scheduling Problems with TimeDependent Resource Constraints. Automation in Construction, 20: 1110-1119. doi:10.1016/j.autcon.2011.04.012

Liu, S. S., \& Wang, C. J. (2012). Optimizing Linear Project Scheduling with Multi-Skilled Crews. Automation in Construction, 24: 16-23. doi:10.1016/j.autcon.2011.12.009

Lounis, Z., \& Vanier, D. J. (200o). A Multiobjective and Stochastic System for Building Maintenance Management. Computer-Aided Civil and Infrastructure Engineering, 15: 320-329.

Ministry of Public Works. (2007). Peraturan Menteri Pekerjaan Umum Nomor: 45/PRT/M/2007 Tentang Pedoman Teknis Pembangunan Bangunan Gedung Negara. Jakarta: Kementerian Pekerjaan Umum.

Molnarka, G. I., \& Koczy, L. T. (2015). Building Renovation Cost Optimization with The Support of Fuzzy Signature State Machines. Computational Intelligence in Information System, 129-138. doi: 10.1007/s11367-013-0548-6

Ostermeyer, Y., Holger, W., \& Reuter, F. (2013). Multidimensional Pareto Optimization as an Approach for Site-Specific Building Refurbishment Solutions Applicable for Life Cycle Sustainability Assessment. International Journal of Life Cycle Assessment, 18: 1762-1779. doi: 10.1007/s11367-013-0548-6

Pun, K., Tsang, K., Choy, V. T., \& Lam, H. (2017). A Fuzzy-AHP-Based Decision Support System for Maintenance Strategy Selection in Facility Management. PICMET'17 Conference Technology Management for Interconnected World. Portland: PICMET.

Ravirala, V., \& Givas, D. (1994). Goal Programming Methodology for Developing an Integrated Pavement Maintenance and Bridge Program. ASCE Journal of Transportation, 121(4): 345-351.

Rossi, F., Van Beek, P., \& Walsh, T. (Eds.). (2006). Handbook of Constraint Programming. Elsevier. Taillandier, F., Fernandez, C., \& Ndiaye, A. (2017). Real Estate Property Maintenance Optimization Based on Multiobjective Multidimensional Knapsack Problem. Computer-Aided Civil and Infrastructure Engineering, 32: 227-251. doi: 10.1111/mice.12246

Wordsworth, P., \& Lee, R. (2001). Lee's Building Maintenance Management. London: Blackwell Science. 